\title{
openheart Change in cardiovascular risk assessment tool and updated Norwegian guidelines for cardiovascular disease in primary prevention increase the population proportion at risk: the Tromsø Study 2015-2016
}

\author{
Amalie Nilsen (D , ,,2 Tove Aminda Hanssen, ${ }^{3,4}$ Knut Tore Lappegård, ${ }^{2,5}$ \\ Anne Elise Eggen, ${ }^{1}$ Maja-Lisa Løchen (1) , ${ }^{1,3}$ Randi Marie Selmer, ${ }^{6}$ Inger Njølstad, ${ }^{1}$ \\ Tom Wilsgaard, ${ }^{1}$ Laila A Hopstock ${ }^{1}$
}

\begin{abstract}
- Additional supplemental material is published online only. To view, please visit the journal online (http://dx.doi.org/10.
\end{abstract} 1136/openhrt-2021-001777).

To cite: Nilsen A, Hanssen TA, Lappegård KT, et al. Change in cardiovascular risk assessment tool and updated Norwegian guidelines for cardiovascular disease in primary prevention increase the population proportion at risk: the Troms $\emptyset$ Study 2015-2016. Open Heart 2021;8:e001777. doi:10.1136/ openhrt-2021-001777

Received 9 July 2021 Accepted 2 August 2021

\section{D) Check for updates}

(c) Author(s) (or their employer(s)) 2021. Re-use permitted under CC BY. Published by BMJ.

For numbered affiliations see end of article.

\section{Correspondence to}

Amalie Nilsen; amalie.nilsen@ uit.no

\section{ABSTRACT}

Aims To compare the population proportion at high risk of cardiovascular disease (CVD) using the Norwegian NORRISK 1 that predicts 10-year risk of CVD mortality and the Norwegian national guidelines from 2009, with the updated NORRISK 2 that predicts 10-year risk of both fatal and non-fatal risk of CVD and the Norwegian national guidelines from 2017.

Methods We included participants from the Norwegian population-based Troms $\emptyset$ Study (2015-2016) aged 40-69 years without a history of CVD $(n=16566)$. The total proportion eligible for intervention was identified by NORRISK 1 and the 2009 guidelines (serum total cholesterol $\geq 8 \mathrm{mmol} / \mathrm{L}$, systolic blood pressure $\geq 160 \mathrm{~mm}$ $\mathrm{Hg}$ or diastolic blood pressure $\geq 100 \mathrm{~mm} \mathrm{Hg}$ ) and NORRISK 2 and the 2017 guidelines (serum total cholesterol $\geq 7 \mathrm{mmol} / \mathrm{L}$, low density lipoprotein (LDL) cholesterol $\geq 5 \mathrm{mmol} / \mathrm{L}$, systolic blood pressure $\geq 160 \mathrm{~mm}$ $\mathrm{Hg}$ or diastolic blood pressure $\geq 100 \mathrm{~mm} \mathrm{Hg}$ ).

Results The total proportion at high risk as defined by a risk score was $12.0 \%$ using NORRISK 1 and $9.8 \%$ using NORRISK 2. When including single risk factors specified by the guidelines, the total proportion eligible for intervention was $15.5 \%$ using NORRISK 1 and the 2009 guidelines and $18.9 \%$ using NORRISK 2 and the 2017 guidelines. The lowered threshold for total cholesterol and specified cutoff for LDL cholesterol stand for a large proportion of the increase in population at risk.

Conclusion The population proportion eligible for intervention increased by 3.4 percentage points from 2009 to 2017 using the revised NORRISK 2 score and guidelines.

\section{INTRODUCTION}

Cardiovascular disease (CVD) is a leading cause of death and disability worldwide and an economic burden for the society, thereby calling for an active preventive approach. ${ }^{1}$ Cardiovascular risk prediction tools have been

\section{Key questions}

What is already known about this subject?

- Risk assessment tools and primary prevention guidelines for cardiovascular disease are used to identify individuals eligible for preventive interventions.

- There is a need to balance risk of overtreatment, healthcare cost and potential side effects versus undertreatment.

What does this study add?

- We demonstrate how change of cardiovascular risk assessment tool and updated guidelines increase the population proportion eligible for preventive interventions.

How might this impact on clinical practice?

- New insights into the impact of risk assessment scoring to identify individuals at risk and accurate estimates of the proportion of the total population at risk are essential for health authorities to target interventions.

developed to objectively estimate risk and to guide clinical decision-making on initiating, intensifying or discontinuing medical treatment for CVD primary prevention. ${ }^{2}$ The Framingham Risk Score, developed from the Framingham Heart Study in the USA, was the first and most broadly used risk score, and several other risk scores have been developed later. ${ }^{3}$ The European guidelines for CVD primary prevention included the Framingham Risk Score in 1994 and $1998,{ }^{45}$ but studies found the risk score to overestimate risk in European populations. ${ }^{6} 7$ The Systematic Coronary Risk Evaluation (SCORE) risk chart was developed from European cohort studies, and separate 
risk charts have been developed for low-risk and high-risk regions in Europe. ${ }^{8}$ CVD primary prevention guidelines highlight the use of cardiovascular risk assessment tools to identify high-risk individuals and to indicate when to start treatment, through risk assessment scoring and treatment guidelines for single risk factors. ${ }^{9}{ }^{10}$ In Norway, the 2009 guidelines for CVD primary prevention ${ }^{11}$ recommended the use of a risk assessment tool to identify high-risk individuals and proposed NORRISK 1, a national calibrated variant of the SCORE prediction model to predict 10-year risk of fatal CVD. ${ }^{12}$ The guideline revision in $2017^{13}$ recommended the updated risk assessment tool NORRISK 2 to predict 10-year risk of both fatal and non-fatal CVD. ${ }^{14}$

Guideline updates will change the definition of the population at risk. Lowering the threshold for defining individuals at high risk and eligible for primary prevention of CVD causes a larger proportion of individuals in need of lifestyle changes and potentially drug treatment with antihypertensives and/or lipid-lowering drugs. However, a change in threshold can also result in the potential of preventing more fatal and non-fatal events of CVD. There is a need for balancing between the risk of undertreatment with risk of disease or death and overtreatment, medication-related side effects, financial cost and healthcare priorities. ${ }^{15-17}$ The aim of this study was to compare the population proportion at risk and eligibility for intervention as defined by NORRISK 1 and the Norwegian national guidelines from 2009 with NORRISK 2 and the national guidelines from 2017 using a Norwegian population-based sample.

\section{METHODS}

\section{Study population}

The Tromsø Study is an ongoing population-based cohort study in the municipality of Troms $\varnothing$, Northern Norway. The study includes seven surveys conducted between 1974 and 2016 (Tromsø 1-7). Both total birth cohorts and representative samples of the population have been invited, and a total of 45473 women and men have participated in one or more surveys (attendance 65\%-79\%). ${ }^{18}$ Data collection includes questionnaires, interviews, biological sampling and clinical examinations. In this study, we included participants from Troms $\varnothing$ (2015-2016), to which all inhabitants aged 40 years or older $(\mathrm{n}=32591)$ were invited, and 21083 women and men participated (65\%). We excluded participants 70 years and older $(n=3437)$, those with previous myocardial infarction (MI) or stroke $(\mathrm{n}=704)$ and those without valid data for NORRISK 1 and NORRISK 2 risk calculation $(\mathrm{n}=376)$, leaving 16566 participants for the current analysis. All participants gave written informed consent. The study was approved by the Regional Committee for Medical and Health Research Ethics North (reference 1778/2015).

\section{Case validation}

Cases of MI and stroke were recorded and validated from study entry until 31 December 2014 by the Troms $\varnothing$ Study CVD registry and were available for all participants attending Troms $\varnothing 7$ and one or more of the previous six surveys. Adjudication of hospitalised and out-of-hospital events was performed by an independent end-point committee reviewing medical records and medical notes, autopsy records and death certificates. The national unique 11-digit identification number allowed linkage to national and local diagnosis registries. Cases of MI and stroke were identified by linkage to the discharge diagnosis registry at the University Hospital of North Norway, the only hospital in the area, with search for International Classification of Diseases described in detail elsewhere. ${ }^{19}$ Due to the lack of validated endpoints after 2014 and among participants attending Troms $\varnothing 7$ only, we also used self-reported MI or stroke ('Have you had a heart attack?' and 'Have you had a stroke?') to exclude individuals with previous MI or stroke.

\section{Measurements}

Self-reported data on smoking, diabetes, family history of coronary heart disease (CHD) and use of lipid-lowering and antihypertensive medication were collected via questionnaires. For medication use, a combination of a question ('Do you use blood pressure lowering drugs?' and 'Do you use lipid-lowering drugs?') and information from a self-reported written list of brand names of regularly used medication (antihypertensives (ATC codes C02, C03, C07, C08 and C09) and lipid-lowering drugs (ATC code C10) was used. Blood pressure was measured on the right arm of all participants (unless in circumstances where this was not possible) three times at $1 \mathrm{~min}$ intervals after 2 min seated rest by a Dinamap ProCare 300 monitor (GE Healthcare, Norway), and the mean of the two final readings was used in the analysis. Non-fasting venous blood samples were collected with standard methods, and the samples were analysed within 48 hours for total, LDL and high density lipoprotein (HDL) cholesterol by enzymatic colorimetric methods (with Roche Diagnostics, Mannheim, Germany) and glycated haemoglobin (HbA1c) by high-performance liquid chromatography (with Tosoh G8, Tosoh Bioscience, San Francisco, USA) at the department of laboratory medicine, University Hospital of North Norway. Trained personnel performed all measurements.

\section{NORRISK 1 and the 2009 guidelines}

The multivariable CVD risk assessment tool NORRISK 1 is a Norwegian adaption of the European SCORE model and predicts 10-year risk (\%) of death due to atherosclerotic CVD in individuals aged $40-69$ years. ${ }^{12}$ Together with the Norwegian guidelines from 2009, NORRISK intended to identify high-risk individuals and guide decision-making in CVD primary prevention. The 10-year risk estimation is based on age, sex, systolic blood pressure, serum total cholesterol and daily smoking habits. Additional risk factors $\mathrm{HbA1c}$ levels and first-degree family member with a history of premature CHD were used to recalculate risk with specific cut-offs. ${ }^{11}{ }^{12}$ Age-specific thresholds are set to determine need of lifestyle advice and/or therapy with 
antihypertensives and/or lipid-lowering drugs, where indication to initiate treatment is set to NORRISK 1 score: $40-49$ years score $\geq 1 \%, 50-59$ years score $\geq 5 \%$ and $60-69$ years score $\geq 10 \%$. The 2009 guideline defined individuals with elevated values of total cholesterol $\geq 8 \mathrm{mmol} / \mathrm{L}$, systolic blood pressure $\geq 160 \mathrm{~mm} \mathrm{Hg}$ or diastolic blood pressure $\geq 100 \mathrm{~mm} \mathrm{Hg}$ to be eligible for intervention regardless of their NORRISK 1 score. In this study, we also calculated the proportion eligible for intervention based on the international definition of hypertension: blood pressure $\geq 140 / 90 \mathrm{~mm} \mathrm{Hg}$.

\section{NORRISK 2 and the 2017 guidelines}

In 2017, the revised national guidelines for CVD prevention were introduced, and an updated and revised risk assessment tool, NORRISK 2, was presented to identify high-risk individuals eligible for intervention. ${ }^{13}$ NORRISK 2 predicts the 10-year risk (\%) of incident MI and stroke combined, including both non-fatal and fatal events of CHD and stroke. The 10-year risk estimation is based on age, sex, systolic blood pressure, serum total cholesterol, daily smoking habits, first-degree family member with a history of premature MI (before the age of 60 years), low serum HDL cholesterol based on sex specific cut-off values $(1.0 \mathrm{mmol} / \mathrm{L}$ in men and $1.3 \mathrm{mmol} / \mathrm{L}$ in women) and use of antihypertensives (where current use increases the score). Selmer et $a l^{14}$ suggest age-specific thresholds in age groups 45-54, 55-64 and 65-74 years to determine whether an individual is at low, medium or high risk of CVD. Elevated values on single risk factors, that is, serum total cholesterol $\geq 7 \mathrm{mmol} / \mathrm{L}$, LDL cholesterol $\geq 5 \mathrm{mmol} / \mathrm{L}$ (does not apply for women over 50 years), systolic blood pressure $\geq 160 \mathrm{~mm} \mathrm{Hg}$ or diastolic blood pressure $\geq 100 \mathrm{~mm} \mathrm{Hg}$, identify individuals eligible for intervention regardless of the NORRISK 2 score. In addition, in individuals with diabetes, LDL cholesterol $\geq 2.5 \mathrm{mmol} / \mathrm{L}$ and blood pressure $\geq 140 / 90 \mathrm{~mm} \mathrm{Hg}$ indicate eligibility for intervention. ${ }^{16}$ In this study, we also calculated the proportion eligible for intervention by the international definition of hypertension: blood pressure $\geq 140 / 90 \mathrm{~mm} \mathrm{Hg}$. Additional risk factors (South Asian ethnicity and diagnosis of rheumatoid arthritis) can be used to recalculate the risk score, with specific cutoffs. Abdominal obesity, mental strain and stress are additional risk factors without a specific cut-off value. ${ }^{13}$ In this study, we did not use the proposed additional risk factors to recalculate the NORRISK 2 score.

\section{Statistics}

We calculated means and proportions of cardiovascular risk factors and sociodemographic factors including selfreported education and cardiovascular risk including measured body mass index (BMI) (normal, overweight and obesity defined as <25, 25-29.9 and $30 \mathrm{~kg} / \mathrm{m}^{2}$, respectively) and waist circumference (obesity defined as $\geq 88$ and $\geq 102 \mathrm{~cm}$ in women and men, respectively) and self-reported current diabetes and physical activity level to present study population characteristics (table 1).
We calculated the proportion of participants eligible for intervention according to NORRISK 1 and the 2009 guidelines and NORRISK 2 and the 2017 guidelines (table 2), overall and stratified by sex and age groups. In addition, we calculated the proportion eligible for intervention using NORRISK 1 without the additional risk factors HbAlc level and family history of premature CHD (online supplemental table 1). We also recalculated the proportion in need of intervention with systolic blood pressure $\geq 140 \mathrm{~mm} \mathrm{Hg}$ and diastolic blood pressure $\geq 90 \mathrm{~mm} \mathrm{Hg}$ as cut-off (online supplemental table $2)$. To compare sex differences, we used t-tests for continuous variables and $\chi^{2}$ tests for categorical variables and McNemar test for pairwise data comparing differences in risk score. Results were considered statistically significant when a $p$ value less than $5 \%$ was attained. To visualise the overlap of high-risk participants defined by NORRISK 1 and NORRISK 2 scores, as well as risk score with additional risk factors from the concurrent guidelines, we present area-proportional Venn diagrams (figure 1), overall and by sex. All analyses were performed using Stata V.16 (StataCorp, 2019; Stata Statistical Software).

\section{RESULTS}

\section{Study population and CVD risk factors}

Study population characteristics are presented in table 1 . Mean age was 53 years for both sexes. Compared with women, men had higher LDL cholesterol, blood pressure, prevalence of obesity (BMI $>30 \mathrm{~kg} / \mathrm{m}^{2}$ ), diabetes, sedentary lifestyle and use of lipid-lowering drugs and antihypertensives but lower HDL cholesterol, prevalence of smoking, abdominal obesity and a lower proportion with higher education.

\section{NORRISK 1 versus NORRISK 2}

The total proportion at high risk (ie, eligible for intervention) defined by risk score only was $12.0 \%$ for NORRISK 1 and $9.8 \%$ for NORRISK 2 (table 2). The proportion of high-risk individuals using NORRISK 1 was $8.6 \%$ calculated without the additional risk factors $\mathrm{HbAlc}$ and family history (online supplemental table 1). In all age groups, a higher proportion of men than women was defined as high-risk individuals $(\mathrm{p}<0.001)$ (table 2). Among men aged 40-49 years, a larger proportion was identified as high risk using NORRISK 1 compared with NORRISK 2 $(p<0.001)$, whereas in men aged $50-59$ years, more men were identified as high risk using NORRISK $2(p<0.001)$.

\section{Total proportion eligible for intervention}

The total proportion eligible for intervention identified by risk score or elevated values for single CVD risk factors was 3.4 percentage points higher using NORRISK 2 and the 2017 guidelines compared with NORRISK 1 and the 2009 guidelines $(18.9 \%$ vs $15.5 \%)$. The total proportion eligible for intervention was higher using NORRISK 2 and the 2017 guidelines in both sexes and all age groups, except among men aged 40-49 years (table 2). In women, the proportion eligible for intervention increased by 3.0 percentage 
힐

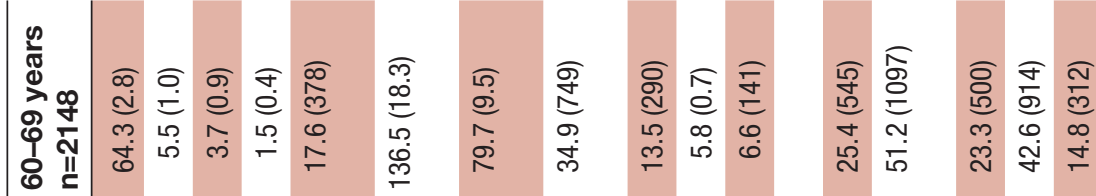

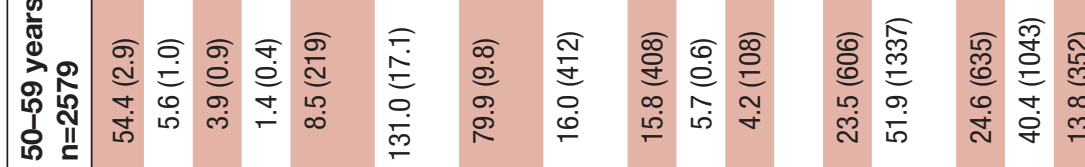

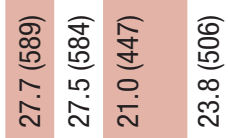

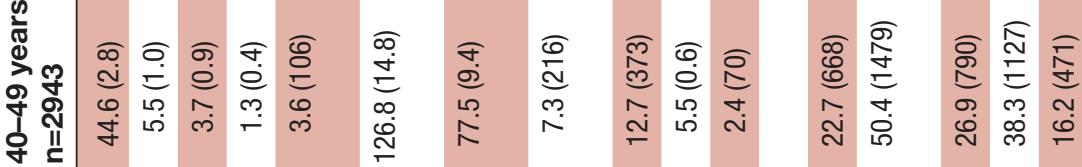

产

吕

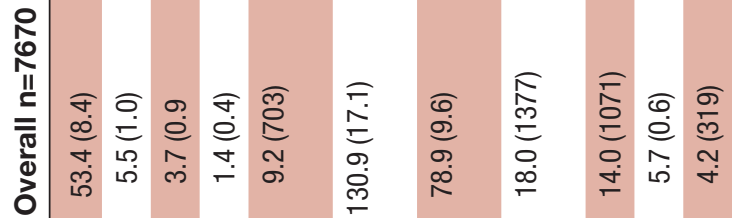

क

চ

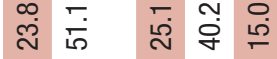

I

$\stackrel{9}{7}$

$\overrightarrow{\overline{\mathrm{S}}}$

듬

$\frac{\overline{\bar{N}}}{\bar{\sigma}}$

क

$\overrightarrow{0}$

$\overrightarrow{\vec{\omega}}$

$\frac{1}{8}$

กับ

N

\&

ฟ 


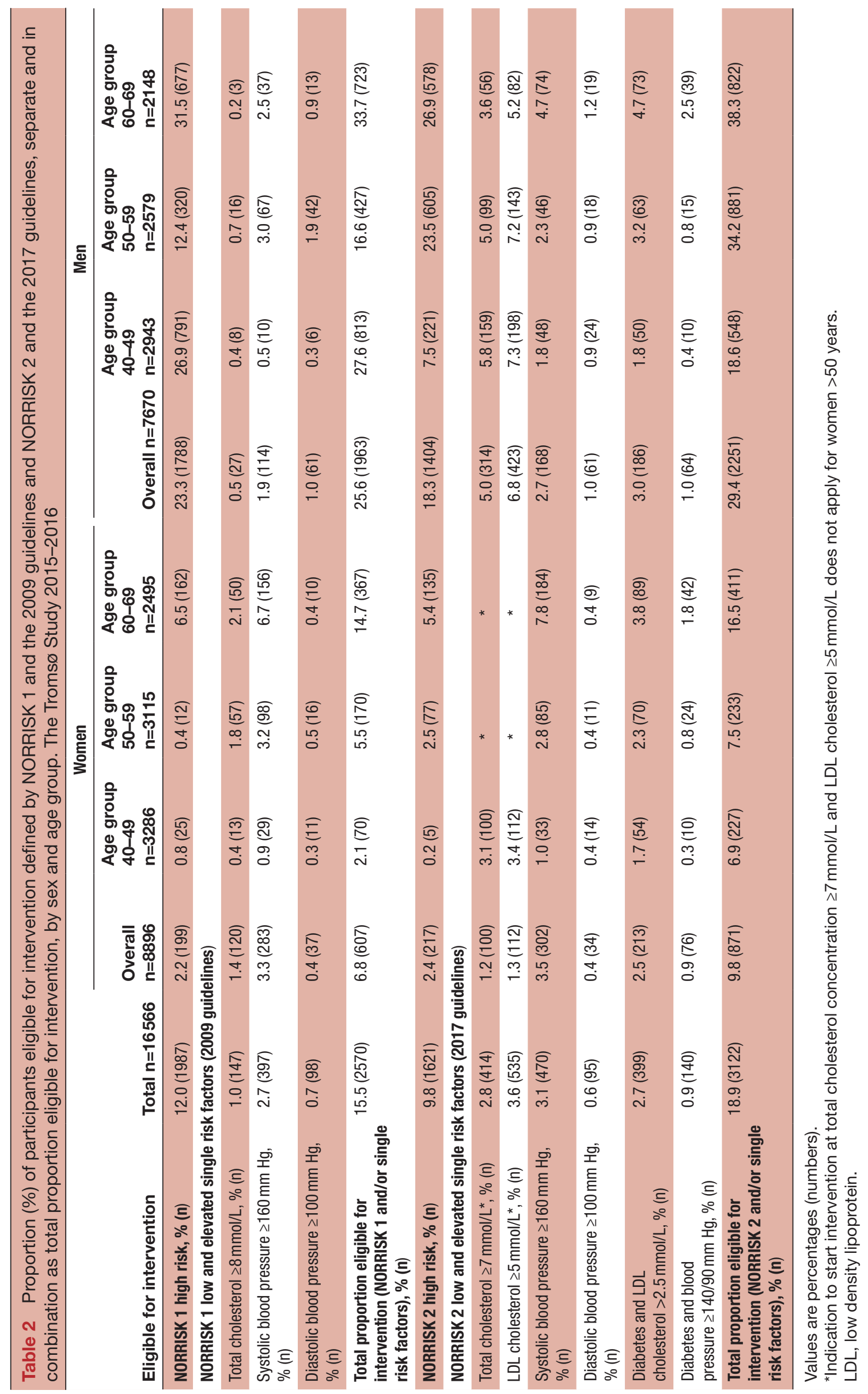


A

Eligible for intervention based on risk score

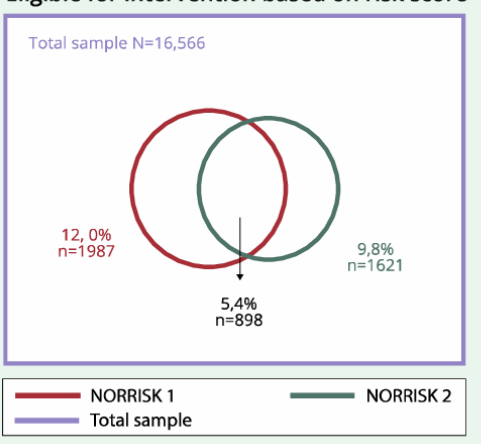

Eligible for intervention based on risk score

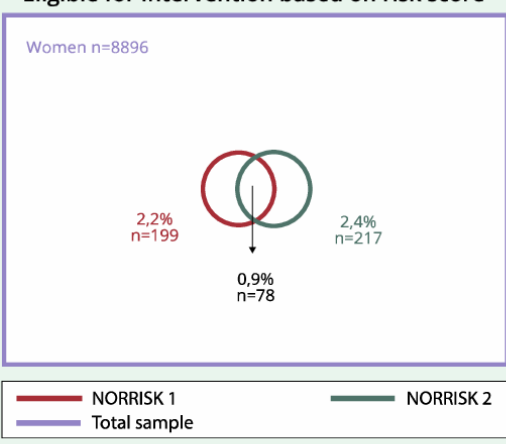

Eligible for intervention based on risk score

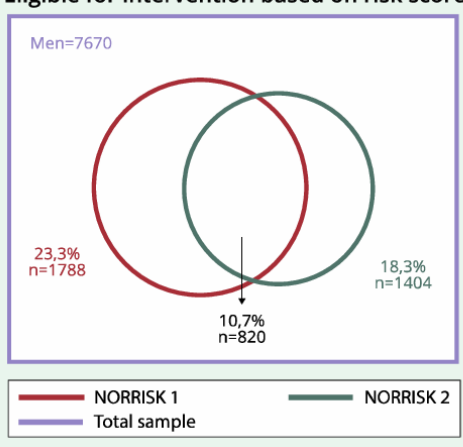

B

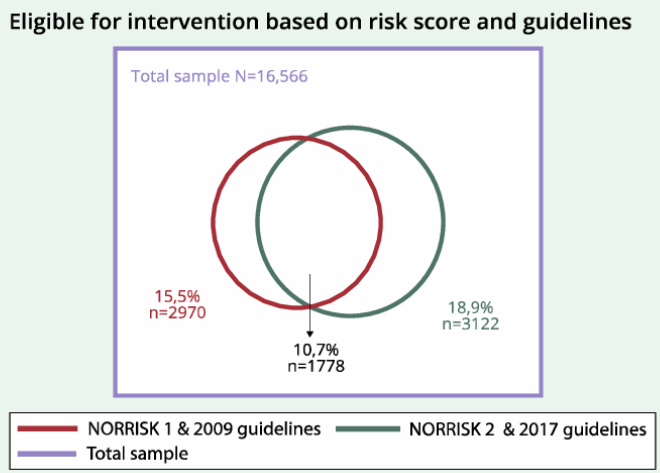

Eligible for intervention based on risk score and guidelines

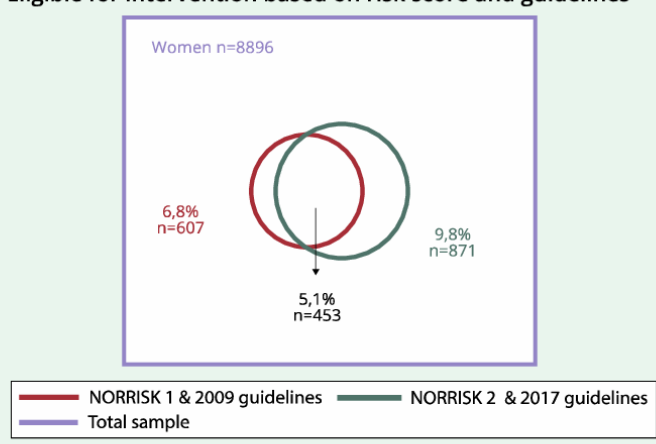

Eligible for intervention based on risk score and guidelines

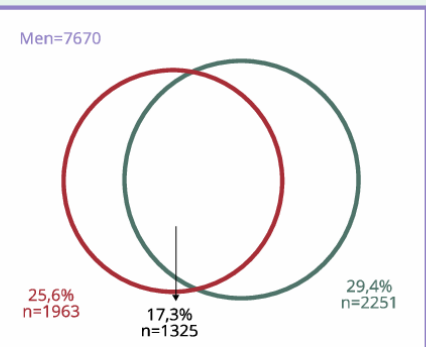

NORRISK 1 \& 2009 guidelines NORRISK 2 \& 2017 guidelines Total sample

Figure 1 Venn diagram presenting the overlap of identification of high-risk participants defined by NORRISK 1 (red circle) and NORRISK 2 (green circle) in the total sample (purple square) (panel A) and NORRISK 1 and NORRISK 2 combined with single risk factors in 2009 (red circle) and 2017 (green circle) guidelines in the sample (purple square) (panel B) by sex. The Tromsø Study 2015-2016.

points from $6.8 \%$ to $9.8 \%$, and the increase among men was 3.8 percentage points from $25.6 \%$ to $29.4 \%$ by NORRISK 1 and the 2009 guidelines, compared with NORRISK 2 and the 2017 guidelines, respectively. Overall, participants defined as being at low risk by risk score were to a greater extent identified as eligible for intervention by single risk factors when using the 2017 guidelines compared with the 2009 guidelines. This was due to change in the cut-off value for serum total cholesterol and the introduction of a specified value for LDL cholesterol. One percent of the participants with low risk by NORRISK 1 had total cholesterol above the threshold of $\geq 8 \mathrm{mmol} / \mathrm{L}$, whereas the lowering of the threshold in the 2017 guideline to $\geq 7 \mathrm{mmol} / \mathrm{L}$ increased the proportion to $2.8 \%$ in individuals with low risk by NORRISK 2. Specifying a threshold for LDL cholesterol to $\geq 5 \mathrm{mmol} / \mathrm{L}$ in the 2017 guideline identified $3.6 \%$ individuals above threshold among individuals identified as low risk by NORRISK 2. Among participants defined as being at low risk by NORRISK 1 , systolic blood pressure identified an additional $2.7 \%$ of the study population as high risk with the 2009 guideline, and $3.1 \%$ of participants defined as low risk by NORRISK 2 were identified as being at high risk by the 2017 guidelines. When including the diabetes-specific threshold in the 2017 guidelines for those with self-reported diabetes, $2.7 \%$ had LDL cholesterol $\geq 2.5 \mathrm{mmol} / \mathrm{L}$, and $0.9 \%$ had blood pressure $\geq 140 / 90 \mathrm{~mm} \mathrm{Hg}$ but were defined as low risk by NORRISK 2. A larger proportion of women compared with men was identified as eligible for intervention by single risk factors only using the 2009 guidelines, while applying single risk factors only to the 2017 guidelines identified a 
higher proportion of men than women eligible for intervention. When we recalculated the total proportion eligible for intervention based on systolic blood pressure $\geq 140 \mathrm{~mm} \mathrm{Hg}$ and diastolic blood pressure $\geq 90 \mathrm{~mm} \mathrm{Hg}$, we found $29.3 \%$ based on NORRISK 1 and the 2009 guidelines and 32.4\% using NORRISK 2 and the 2017 guidelines (online supplemental table 2).

\section{Overlap between risk scores only and risk scores and the guidelines combined}

Among individuals identified as high risk by risk score only, NORRISK 1 identified in total $12.0 \%$ (2.2\% of women and $23.3 \%$ of men) as high risk, while NORRISK 2 identified in total $9.8 \%$ (2.4\% of women and $18.3 \%$ of men) as high risk. The overlapping proportion identified as high risk in both risk scores was in total $5.4 \%(0.9 \%$ of women and $10.7 \%$ of men). Combining NORRISK 1 and the 2009 guidelines, $15.5 \%$ in total $(6.8 \%$ women and $25.6 \%$ men) was identified as eligible for intervention, while when using NORRISK 2 and the 2017 guidelines, the proportion was $18.9 \%$ in total (9.8\% women and $29.4 \%$ men). Overall, the overlapping proportion of $10.7 \%$ ( $5.1 \%$ women and $17.3 \%$ men) was identified as eligible for intervention in both risk scores with their respective guidelines (figure 1).

\section{DISCUSSION}

In this study, we compared the proportion at high CVD risk and eligible for intervention using two consecutive versions of guidelines and risk assessment tools in a Norwegian general population of women and men aged 40-69 years. The main finding is that the proportion eligible for intervention increased from $15.5 \%$ using the risk assessment tool NORRISK 1 and the 2009 guidelines to $18.9 \%$ using the revised NORRISK 2 and the 2017 guidelines.

\section{Change in cardiovascular risk assessment tool}

The proportion of high-risk individuals defined by risk score only was lower using the updated NORRISK 2 compared with the previous NORRISK 1 . This can be explained by the fundamental differences in the risk scores, as they measure different endpoints and thus are not directly comparable. NORRISK 1 predicts 10-year risk of fatal CVD, whereas NORRISK 2 predicts the 10-year risk of MI, stroke and fatal CVD. ${ }^{12} 14$ The European guidelines for CVD primary prevention encourage the calibration of risk assessment tools to the target population by adjusting for secular changes in risk factor levels and CVD mortality. ${ }^{20}$ A reduction over time in the major CVD risk factors serum total cholesterol, blood pressure and smoking in the general population has been shown both in large international studies ${ }^{21}{ }^{22}$ and in the Troms $\varnothing$ Study population, ${ }^{19} 2324$ and we have previously demonstrated a decline in total CVD risk in the Tromsø Study ${ }^{25}$ similar to findings from the $\mathrm{UK}^{26}$ and the USA. ${ }^{27}$ Further, there has been a major decline in mortality and morbidity of CVD in Norway. ${ }^{28}$ The reduction in risk factors, morbidity and mortality over time can explain the lower proportion eligible for intervention by the updated risk assessment tool NORRISK 2. NORRISK 1 is a national calibrated version of the European SCORE algorithm, based on national mortality rates from 1993 to 2003, and mean level risk factors from Norwegian Health Surveys from 2000 to 2003, ${ }^{12}$ while NORRISK 2 is based on the 10-year follow-up of a large population-based cohort (Cohort of Norway (CONOR)) through linkage to the Cardiovascular Disease in Norway (CVDNOR) project, a database of CVD hospital discharge diagnoses and mortality in Norway in 1994-2009. ${ }^{14}$ Another explanation of this finding can be the use of additional risk factors in our analysis, where we included additional risk factors in the calculation of NORRISK 1 (HbAlc levels and family history of CHD) and did not include the additional risk factors (rheumatoid arthritis, South Asian ethnicity, abdominal obesity and/or mental stress) in the calculation of NORRISK 2. A recent study found NORRISK 2 to underestimate CVD risk in South Asians and proposed an update (NORRISK 2-SADia) improving the predictions of 10-year risk in this population. ${ }^{29}$ In our study, valid data regarding the proposed additional risk factors with specified cut-offs (ethnicity and diagnosis of rheumatoid arteritis) were not available. ${ }^{30}$ Almost half of the study population had abdominal obesity, and in real patient consultations, this could lead to a higher proportion at high risk using NORRISK 2. However, this risk factor is without a multiplication factor and hence not used to calculate the proportion eligible for intervention in this study.

\section{Single risk factors defined in treatment guidelines}

In this study, we found that the updated risk score with additional guidelines increased the proportion of participants eligible for intervention, where the decrease in threshold for total cholesterol levels and a defined value of LDL cholesterol stand for a large proportion of this increase. The impact on the risk of CVD by lowering cholesterol levels is well known. A lowering of LDL cholesterol levels by $1 \mathrm{mmol} / \mathrm{L}$ corresponds to a $20 \%-25 \%$ reduction in non-fatal MI and death due to CVD. ${ }^{10}$ Our findings are in line with a study from Denmark where the authors found that the updated 2019 European Society of Cardiology/European Atherosclerosis Society (ESC/EAS) guidelines doubled the proportion of individuals eligible for statin therapy compared with the previous guidelines, ${ }^{31}$ findings that are similar to other studies. ${ }^{32} 33$

For blood pressure, there was no difference in threshold between the 2009 and 2017 guidelines where systolic blood pressure $\geq 160 \mathrm{~mm} \mathrm{Hg}$ and diastolic blood pressure $\geq 100 \mathrm{~mm}$ Hg urge immediate start of pharmacological treatment (regardless of NORRISK score), in line with the European ESC/EAS guidelines. ${ }^{34}$ In the American College of Cardiology/American Heart Association (ACC/AHA) guidelines, the recommendation is that blood pressure $\geq 140 / 90 \mathrm{~mm} \mathrm{Hg}$ should lead to direct initiation of antihypertensive drugs. ${ }^{35}$ Hypertension is defined as blood pressure $\geq 140 / 90 \mathrm{~mm} \mathrm{Hg}$; however, in Norway, lifestyle modification is encouraged before starting medical treatment. By replacement of blood pressure cut-off from $\geq 160 / 100 \mathrm{~mm} \mathrm{Hg}$ to $\geq 140 / 90 \mathrm{~mm}$ $\mathrm{Hg}$, we found that the proportion eligible for intervention by NORRISK 1 and the 2009 guidelines increased by 
13.8 percentage points, and when using NORRISK 2 and the 2017 guidelines, the proportion eligible for intervention increased by 13.4 percentage points. However, in the important debate regarding treatment target in blood pressure levels in primary prevention, it has been suggested that lifestyle modification should be emphasised to a larger degree before initiating pharmacological treatment. ${ }^{36}$

\section{Combining risk score and additional risk factors}

To the best of our knowledge, there have been few previous studies combining both risk score assessment tools and additional guidelines to compare the proportion at risk of CVD and eligibility of intervention in a general population. A study from Germany used the risk assessment tool SCORE Deutschland with additional risk factors (diabetes, total cholesterol $\geq 8 \mathrm{mmol} / \mathrm{L}$, renal insufficiency and stage 3 hypertension (blood pressure $\geq 180 / 110 \mathrm{~mm} \mathrm{Hg}$ ) ) and found $13.4 \%$ of the study population to be at high risk of 10-year CVD mortality. ${ }^{37}$ Interestingly, the authors found that among men, the majority of high-risk individuals were eligible for intervention because of SCORE $\geq 5 \%$, contrary to women where the majority of women were classified as high risk based on additional risk factors, ${ }^{37}$ which is in line with our findings. Other studies have also found that adding comorbidities and single risk factors increases the proportion of individuals at high risk, demonstrating the challenge of comparing our findings with other studies. ${ }^{38} 39$

In conclusion, we found that updated CVD primary prevention guidelines increased the proportion at risk and eligible for intervention by 3.4 percentage points in individuals aged 40-69 years, where the increase was 3.0 percentage points in women and 3.8 percentage points in men. In Norway, there are about 2.1 million inhabitants aged 40-69 years. ${ }^{40}$ Therefore, this increase causes almost 70000 more individuals eligible for intervention using NORRISK 2 and the 2017 guidelines in this age group. Individuals identified to be at high risk and eligible for intervention may be given the opportunity from their primary physician to make necessary lifestyle changes. The guideline ${ }^{13}$ suggests that individuals at high risk are given 3-12 months to make changes such as smoking cessation, increased physical activity and dietary changes to lower blood pressure and cholesterol levels before considering initiating drug treatment with antihypertensives and/or lipid-lowering drugs. However, among individuals with very high blood pressure, cholesterol levels or high total risk, drug treatment may be initiated directly. An increase of 3.4 percentage points means a higher number of individuals in need of time from their primary physician to give lifestyle advice, follow up the effect of this advice and assess whether to start drug treatment. Among individuals that start drug treatment, there is a need for follow-up to evaluate drug efficacy and whether treatment targets are achieved, as well as side effects. Change in the guidelines of CVD prevention may lead to a higher burden of the healthcare system, but this also translates into a higher number of individuals who can avoid a fatal or non-fatal event of CVD. The main goal in the use of risk assessment tools is to identify the right individuals to keep the balance between avoiding the potential negative effects such as side effects, overtreatment, undertreatment and a higher cost for the healthcare system on one side and preventing high-risk individuals from developing CVD on the other. ${ }^{2}$

\section{CONCLUSION}

The population proportion eligible for intervention increased by 3.4percentage points from 2009 to 2017 using the revised NORRISK 2 score and guidelines, where the lowering of threshold in total cholesterol and specified cutoff for LDL cholesterol stand for a large proportion of the increase in population at risk.

\section{Strengths and limitations}

A strength of this study is the use of a sample from a large population-based study, with validated endpoints for exclusion of prevalent cases and risk factor measurements performed by trained personnel using standardised protocols and instruments. A limitation is that participants in population-based studies in general tend to be healthier than non-attenders. This potential selection bias might cause underestimation of the true population proportion in need of intervention.

\section{Author affiliations}

${ }^{1}$ Department of Community Medicine, UiT The Arctic University of Norway, Troms $\emptyset$, Norway

${ }^{2}$ Department of Medicine, Nordlands Hospital, Bodo, Norway

${ }^{3}$ Department of Cardiology, University Hospital of North Norway, Troms $\emptyset$, Norway

${ }^{4}$ Department of Health and Care Sciences, UiT The Arctic University of Norway,

Tromsø, Norway

${ }^{5}$ Department of Clinical Medicine, UiT The Arctic University of Norway, Troms $\emptyset$,

Norway

${ }^{6}$ Department of Infectious Disease Epidemiology and Modelling, Norwegian Institute of Public Health, Oslo, Norway

\section{Twitter Laila A Hopstock @lailahopstock}

Acknowledgements We would like to thank all participants and all technicians in the Tromsø Study for their important contribution.

Contributors $\mathrm{LAH}$ and AN contributed to the conception and design of the work. AEE, M-LL, IN and TW contributed to the data acquisition. AN and TW contributed to the data analysis. AN drafted the manuscript. TAH, KTL, AEE, M-LL, RMS, IN, TW and LAH critically revised the manuscript. All authors contributed to the interpretation of the work and gave final approval and agreed to be accountable for all aspects of the work ensuring integrity and accuracy.

Funding The first author PhD grant is funded by the Northern Norway Health Authority (grant number HNF1363-17).

Competing interests None declared.

Patient consent for publication Not required.

Provenance and peer review Not commissioned; externally peer reviewed.

Data availability statement Data may be obtained from a third party and are not publicly available.

Supplemental material This content has been supplied by the author(s). It has not been vetted by BMJ Publishing Group Limited (BMJ) and may not have been peer-reviewed. Any opinions or recommendations discussed are solely those of the author(s) and are not endorsed by BMJ. BMJ disclaims all liability and responsibility arising from any reliance placed on the content. Where the content includes any translated material, BMJ does not warrant the accuracy and reliability of the translations (including but not limited to local regulations, clinical guidelines, terminology, drug names and drug dosages), and is not responsible for any error and/or omissions arising from translation and adaptation or otherwise. 
Open access This is an open access article distributed in accordance with the Creative Commons Attribution 4.0 Unported (CC BY 4.0) license, which permits others to copy, redistribute, remix, transform and build upon this work for any purpose, provided the original work is properly cited, a link to the licence is given, and indication of whether changes were made. See: https://creativecommons.org/ licenses/by/4.0/.

\section{ORCID iDs}

Amalie Nilsen http://orcid.org/0000-0002-7462-4778

Maja-Lisa Løchen http://orcid.org/0000-0002-8532-6573

\section{REFERENCES}

1 Roth GA, Johnson C, Abajobir A, et al. Global, regional, and national burden of cardiovascular diseases for 10 causes, 1990 to 2015. J Am Coll Cardiol 2017;70:1-25.

2 Rossello X, Dorresteijn JA, Janssen A, et al. Risk prediction tools in cardiovascular disease prevention: a report from the ESC prevention of CVD programme led by the European Association of Preventive Cardiology (EAPC) in collaboration with the Acute Cardiovascular Care Association (ACCA) and the Association of Cardiovascular Nursing and Allied Professions (ACNAP). Eur J Prev Cardiol 2019;26:1534-44.

3 Anderson KM, Odell PM, Wilson PW, et al. Cardiovascular disease risk profiles. Am Heart J 1991;121:293-8.

4 Pyörälä K, De Backer G, Graham I, et al. Prevention of coronary heart disease in clinical practice. recommendations of the task force of the European Society of Cardiology, European Atherosclerosis Society and European Society of Hypertension. Eur Heart $J$ 1994;15:121-61.

5 Wood D, De Backer G, Faergeman O, et al. Prevention of coronary heart disease in clinical practice: recommendations of the second joint task force of European and other societies on coronary prevention. Atherosclerosis 1998;140:199-270.

6 Bastuji-Garin S, Deverly A, Moyse D, et al. The Framingham prediction rule is not valid in a European population of treated hypertensive patients. J Hypertens 2002;20:1973-80.

7 Emberson J, Whincup P, Morris R, et al. Evaluating the impact of population and high-risk strategies for the primary prevention of cardiovascular disease. Eur Heart J 2004;25:484-91.

8 Conroy RM, Pyörälä K, Fitzgerald AP, et al. Estimation of ten-year risk of fatal cardiovascular disease in Europe: the SCORE project. Eur Heart J 2003;24:987-1003.

9 Goff DC, Lloyd-Jones DM, Bennett G, et al. 2013 ACC/AHA guideline on the assessment of cardiovascular risk: a report of the American College of Cardiology/American heart association Task force on practice guidelines. Circulation 2014;129:S49-73.

10 Piepoli MF, Hoes AW, Agewall S. 2016 European Guidelines on cardiovascular disease prevention in clinical practice: The Sixth Joint Task Force of the European Society of Cardiology and Other Societies on Cardiovascular Disease Prevention in Clinical Practice (constituted by representatives of 10 societies and by invited experts): Developed with the special contribution of the European Association for Cardiovascular Prevention \& Rehabilitation (EACPR). Eur J Prev Cardiol 2016;37:2315-81.

11 Norheim OF GB, Kjeldsen SE. Retningslinjer for individuell primærforebygging AV hjerte- OG karsykdommer. Oslo Helsedirektoratet, 2009. Available: https://docplayer.me/7978075-Is1550-nasjonale-retningslinjer-for-individuell-primaerforebygging-avhjerte-og-karsykdommer.html

12 Selmer R, Lindman AS, Tverdal A, et al. [Model for estimation of cardiovascular risk in Norway]. Tidsskr Nor Laegeforen 2008;128:286-90.

13 The health directory of Norway. Forebygging AV hjerte- OG karsykdommer, 2017. Available: https://www.helsedirektoratet.no/ retningslinjer/forebygging-av-hjerte-og-karsykdom

14 Selmer R, Igland J, Ariansen I, et al. NORRISK 2: a Norwegian risk model for acute cerebral stroke and myocardial infarction. Eur J Prev Cardiol 2017;24:773-82.

15 Stewart J, Addy K, Campbell S, et al. Primary prevention of cardiovascular disease: updated review of contemporary guidance and literature. JRSM Cardiovasc Dis 2020;9:204800402094932.

16 Klemsdal TO, Gjelsvik B, Elling I. New guidelines for the prevention of cardiovascular disease. Tidsskr Nor Laegeforen2017;137.

17 Cooney MT, Dudina A, D'Agostino R, et al. Cardiovascular risk-estimation systems in primary prevention: do they differ? do they make a difference? can we see the future? Circulation 2010;122:300-10.

18 Jacobsen BK, Eggen AE, Mathiesen EB, et al. Cohort profile: the Tromso study. Int J Epidemiol 2012;41:961-7.
19 Mannsverk J, Wilsgaard T, Mathiesen EB, et al. Trends in modifiable risk factors are associated with declining incidence of hospitalized and nonhospitalized acute coronary heart disease in a population. Circulation 2016:133:74-81.

20 Authors/Task Force Members, ESC Committee for Practice Guidelines (CPG), ESC National Cardiac Societies. 2019 ESC/ EAS guidelines for the management of dyslipidaemias: lipid modification to reduce cardiovascular risk. Atherosclerosis 2019;290:140-205.

21 Farzadfar F, Finucane MM, Danaei G, et al. National, regional, and global trends in serum total cholesterol since 1980: systematic analysis of health examination surveys and epidemiological studies with 321 country-years and 3.0 million participants. Lancet 2011;377:578-86.

22 NCD Risk Factor Collaboration (NCD-RisC). Worldwide trends in blood pressure from 1975 to 2015: a pooled analysis of 1479 population-based measurement studies with $19 \cdot 1$ million participants. Lancet 2017;389:37-55.

23 Hopstock LA, Bønaa KH, Eggen AE, et al. Longitudinal and secular trends in blood pressure among women and men in birth cohorts born between 1905 and 1977: the Tromsø study 1979 to 2008. Hypertension 2015;66:496-501.

24 Hopstock LA, Bønaa KH, Eggen AE, et al. Longitudinal and secular trends in total cholesterol levels and impact of lipid-lowering drug use among Norwegian women and men born in 1905-1977 in the population-based Tromsø study 1979-2016. BMJ Open 2017;7:e015001.

25 Nilsen A, Hanssen TA, Lappegård KT, et al. Secular and longitudinal trends in cardiovascular risk in a general population using a national risk model: the Tromsø study. Eur J Prev Cardiol 2019;26:1852-61.

26 Alageel S, Wright AJ, Gulliford MC. Changes in cardiovascular disease risk and behavioural risk factors before the introduction of a health check programme in England. Prev Med 2016;91:158-63.

27 Ford ES. Trends in predicted 10-year risk of coronary heart disease and cardiovascular disease among U.S. adults from 1999 to $2010 . J$ Am Coll Cardiol 2013;61:2249-52.

28 Norwegian Institute of Public Health. Cardiovascular disease in Norway, 2020. Available: https://www.fhi.no/en/op/hin/healthdisease/cardiovascular-disease-in-norway-/

29 Rabanal KS, Igland J, Tell GS, et al. Validation of the cardiovascular risk model NORRISK 2 in South Asians and people with diabetes. Scand Cardiovasc J 2021;55:56-62.

30 Kvien TK, Glennås A, Knudsrød OG, et al. The validity of selfreported diagnosis of rheumatoid arthritis: results from a population survey followed by clinical examinations. J Rheumatol 1996:23:1866-71.

31 Mortensen MB, Nordestgaard BG. 2019 vs. 2016 ESC/EAS statin guidelines for primary prevention of atherosclerotic cardiovascular disease. Eur Heart J 2020;41:3005-15.

32 Pagidipati NJ, Navar AM, Mulder $\mathrm{H}$, et al. Comparison of recommended eligibility for primary prevention statin therapy based on the US preventive services Task force recommendations vs the ACC/AHA guidelines. JAMA 2017;317:1563-7.

33 Pencina MJ, Navar-Boggan AM, D'Agostino RB, et al. Application of new cholesterol guidelines to a population-based sample. $N$ Engl $J$ Med 2014;370:1422-31.

34 Williams B, Mancia G, Spiering W, et al. 2018 ESC/ESH guidelines for the management of arterial hypertension. Eur Heart $J$ 2018;39:3021-104.

35 Whelton PK, Carey RM, Aronow WS, et al. 2017 ACC/AHA/AAPA ABC/ACPM/AGS/APhA/ASH/ASPC/NMA/PCNA guideline for the prevention, detection, evaluation, and management of high blood pressure in adults: executive summary: a report of the American college of cardiology/American Heart Association Task Force on clinical practice guidelines. J Am Coll Cardiol 2018;71:2199-269.

36 Hong KN, Fuster V, Rosenson RS, et al. How Low to Go With Glucose, Cholesterol, and Blood Pressure in Primary Prevention of CVD. J Am Coll Cardiol 2017;70:2171-85.

37 Diederichs C, Neuhauser H, Rücker V, et al. Predicted 10-year risk of cardiovascular mortality in the 40 to 69 year old general population without cardiovascular diseases in Germany. PLOS One 2018;13:e0190441.

38 Karjalainen T, Adiels M, Björck L, et al. An evaluation of the performance of SCORE Sweden 2015 in estimating cardiovascular risk: the Northern Sweden MONICA study 1999-2014. Eur J Prev Cardiol 2017;24:103-10

39 Holm A-SS, Olsen GS, Borglykke A, et al. Estimating the proportion of Danes at high risk of fatal cardiovascular disease. Scand J Public Health 2011;39:571-6.

40 Norway S. Population by age. statistical variable and year, 2021. Available: http://www.ssb.no/en/statbank/table/07459 